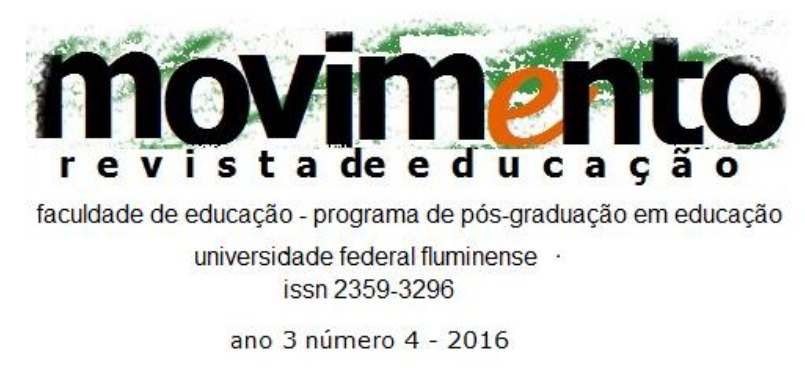

\title{
EDUCAÇÃO ESCOLAR, CURRÍCULO E SOCIEDADE: o problema da Base Nacional Comum Curricular
}

\author{
Dermeval Saviani ${ }^{1}$
}

\section{RESUMO}

Este artigo trata das relações entre escola, currículo e sociedade com foco no conteúdo específico da educação escolar tendo como objetivo subsidiar a discussão sobre a base nacional comum curricular. Para tanto, parte do próprio conceito de currículo situandoo em suas determinações sociais para tratar, em seguida, dos saberes que, direta ou indiretamente, entram na composição dos currículos formativos destinados a preparar os educandos para se inserir de forma ativa e crítica na vida social. Sobre essa base aborda a questão da base nacional comum curricular apresentando um delineamento do conteúdo curricular da educação básica visando superar os limites da proposta apresentada oficialmente no atual contexto.

Palavras-chave: Educação escolar brasileira; Currículo e sociedade; Base nacional comum curricular.

\section{RESUMEN}

El artículo se ocupa de las relaciones entre la escuela, el plan de estudios y la sociedad centrándose en el contenido específico de la educación escolar. Su objetivo es subsidiar los debates sobre la base nacional común del plan de estudios en Brasil. Por lo tanto analiza primeramente el concepto mismo de plan de estudios, sus determinaciones sociales para no que sigue analizar los saberes que directo o indirectamente compone los planes de estudios de capacitación con el propósito de preparar a los estudiantes para una vida activa y crítica en la sociedad. Con el fin de superar los límites de la propuesta presentada oficialmente en el contexto actual, el artículo presenta un esbozo del contenido del plan de estudios en la educación básica

Palabras-clave: Educación escolar brasileira; Plan de estudios y sociedad; Base nacional común de planes de estudios.

\footnotetext{
1 Professor Emérito da UNICAMP, Pesquisador Emérito do CNPq, Coordenador Geral do Grupo Nacional de Estudos e Pesquisas "História, Sociedade e Educação no Brasil" (HISTEDBR) e Professor Titular Colaborador Pleno do Programa de Pós-Graduação e Educação da UNICAMP. E-mail: dermeval.saviani.2013@gmail.com
} 


\section{Sobre o conceito de currículo}

Currículo é entendido comumente como a relação das disciplinas que compõem um curso ou a relação dos assuntos que constituem uma disciplina, no que ele coincide com o termo programa. Entretanto, no âmbito dos especialistas nessa matéria tem prevalecido a tendência a se considerar o currículo como sendo o conjunto das atividades (incluído o material físico e humano a elas destinado) que se cumprem com vistas a determinado fim. Este pode ser considerado o conceito ampliado de currículo, pois, no que toca à escola, abrange todos os elementos a ela relacionados.

Em síntese, pode-se considerar que o currículo em ato de uma escola não é outra coisa senão essa própria escola em pleno funcionamento, isto é, mobilizando todos os seus recursos, materiais e humanos, na direção do objetivo que é a razão de ser de sua existência: a educação das crianças e jovens. Poderíamos dizer que, assim como o método procura responder à pergunta: como se deve fazer para atingir determinado objetivo, o currículo procura responder à pergunta: o que se deve fazer para atingir determinado objetivo. Diz respeito, pois, ao conteúdo da educação e sua distribuição no tempo e espaço que lhe são destinados.

Se o currículo diz respeito ao conteúdo da educação, para se saber o sentido do currículo escolar importa tentar responder à pergunta: qual é o conteúdo da educação escolar? A esse respeito parece não haver muitas dúvidas. O conteúdo fundamental da escola se liga à questão do saber, do conhecimento. Mas não se trata de qualquer saber e sim do saber elaborado, sistematizado. $O$ conhecimento de senso comum se desenvolve e é adquirido independentemente da escola. Para o acesso ao saber sistematizado é que se torna necessária a escola. Ora, que implicações tem isso para a questão do currículo? 
Como já foi dito, prevalece entre os especialistas a ideia de que currículo é o conjunto das atividades desenvolvidas pela escola. Portanto, currículo é tudo o que a escola faz; assim não faria sentido falar em atividades extracurriculares. Tal conceito representa, sem dúvida, um avanço em relação à noção corrente que identifica currículo com programa ou elenco de disciplinas. Mas apresenta, também, alguns problemas. Com efeito, se tudo o que acontece na escola é currículo, se se apaga a diferença entre curricular e extracurricular, então tudo acaba adquirindo o mesmo peso; e abre-se o caminho para toda sorte de inversões e confusões que terminam por descaracterizar o trabalho escolar. Com isso, facilmente o secundário pode tomar o lugar daquilo que é principal, deslocando-se, em consequência, para o âmbito do acessório aquelas atividades que constituem a razão de ser da escola.

Não é demais lembrar que esse fenômeno pode ser facilmente observado no dia-a-dia das escolas. Dou apenas um exemplo, tendo por base o calendário das escolas brasileiras: 0 ano letivo começa em fevereiro e logo temos a semana do índio, a semana santa, o dia do trabalho, a semana das mães, dia internacional das famílias, dia mundial do meio ambiente, as festas juninas; em agosto começa o segundo período letivo e logo chega o dia dos pais, a semana do soldado, semana do folclore, depois a semana da pátria, a semana da árvore, os jogos da primavera, semana da criança, festa do professor, do funcionário público, semana da asa, semana da República, festa da bandeira... e nesse momento já chegamos ao final de novembro. $O$ ano letivo se encerra e estamos diante da seguinte constatação: fez-se de tudo na escola; encontrou-se tempo para toda espécie de comemoração, mas muito pouco tempo foi destinado ao processo de transmissão-assimilação de conhecimentos sistematizados.

Mas, pode-se perguntar: qual é o problema? Se tudo é currículo, se tudo o que a escola faz é importante, se tudo concorre para o crescimento e aprendizagem dos alunos, então tudo o que se fez é válido e a escola não deixou de cumprir sua função educativa. No entanto, o que se constata é que, de semana em semana, de comemoração em comemoração, a verdade é que a escola perdeu 
de vista a sua atividade nuclear que é a de propiciar aos alunos o ingresso na cultura letrada assegurando-Ihes a aquisição dos instrumentos de acesso ao saber elaborado. Em suma, o currículo incorporou as mais diversas atividades, mas dedicou pouco tempo para o estudo da língua vernácula, matemática, ciências da natureza, ciências da sociedade, filosofia, artes.

Para contornar esses problemas fui levado, então, a corrigir aquela definição de currículo acrescentando-Ihe o adjetivo nucleares. Com essa retificação, a definição passaria a ser a seguinte: currículo é o conjunto das atividades nucleares desenvolvidas pela escola. Fica, assim, claro que as atividades referentes às comemorações mencionadas são secundárias e não essenciais à escola. Enquanto tais, são extracurriculares e só têm sentido na medida em que possam enriquecer as atividades curriculares, isto é, aquelas próprias da escola, não devendo, em hipótese alguma, prejudicá-las ou substituí-las.

Das considerações feitas resulta importante manter a diferença entre atividades curriculares e extracurriculares, já que esta é uma maneira de não perdermos de vista a distinção entre o que é principal e o que é secundário. Um currículo é, portanto, uma escola funcionando, isto é, uma escola desempenhando a função que lhe é própria.

No entanto, é necessário também não perder de vista que os conhecimentos desenvolvidos no âmbito das relações sociais ao longo da história não são transpostos direta e mecanicamente para o interior das escolas na forma da composição curricular. Isto significa que para existir a escola não basta a existência do saber sistematizado. É necessário viabilizar as condições de sua transmissão e assimilação. Isto implica dosá-lo e sequenciá-lo de modo que a criança passe gradativamente do seu não domínio ao seu domínio. E o saber dosado e sequenciado para efeitos de sua transmissão-assimilação no espaço escolar ao longo de um tempo determinado, é o que convencionamos chamar de "saber escolar". E é nessa condição que os conhecimentos sistematizados passam a integrar os currículos das escolas. 
Em suma, pela mediação da escola, dá-se a passagem do saber espontâneo ao saber sistematizado, da cultura popular à cultura erudita. Mas, se a escola se justifica em função da necessidade de assimilação do conhecimento elaborado, isto não significa que este seja mais importante ou hierarquicamente superior. Trata-se, na verdade, de um movimento dialético, isto é, a ação escolar permite que se acrescentem novas determinações que enriquecem as anteriores e estas, de forma alguma, são excluídas. Ao contrário, o saber espontâneo, baseado na experiência de vida, a cultura popular, portanto, é a base que torna possível a elaboração do saber e, em consequência, a cultura erudita. Isso significa que o acesso à cultura erudita possibilita a apropriação de novas formas pelas quais se podem expressar os próprios conteúdos do saber popular. Mantém-se, portanto, a primazia da cultura popular da qual deriva a cultura erudita que se manifesta como uma nova determinação que a ela se acrescenta. Nessa condição, a restrição do acesso à cultura erudita conferirá, àqueles que dela se apropriam, uma situação de privilégio, uma vez que o aspecto popular não lhes é estranho. A recíproca, porém, não é verdadeira: os membros da população marginalizados da cultura letrada tenderão a encará-la como uma potência estranha que os desarma e domina.

O papel da escola democrática será, pois, o de viabilizar a toda a população o acesso à cultura letrada consoante o princípio que enunciei em outro trabalho (SAVIANI, 2012a) segundo o qual, para se libertar da dominação, os dominados necessitam dominar aquilo que os dominantes dominam. Portanto, de nada adiantaria democratizar a escola, isto é, expandi-la de modo a torná-la acessível a toda a população se, ao mesmo tempo, isso fosse feito esvaziando-se a escola de seu conteúdo específico, isto é, a cultura letrada, o saber sistematizado. Isto significaria, segundo o dito popular, "dar com uma mão e tirar com a outra". Com efeito, como já foi lembrado, para ter acesso ao saber espontâneo, à cultura popular, o povo não precisa da escola. Esta é importante para ele na medida em que the permite o domínio do saber elaborado. 


\section{Currículo e Sociedade}

Mas como se originou esse conteúdo fundamental da escola? Como explicar a constituição desse vínculo entre escola e saber sistematizado?

Para responder a essas questões é necessário considerar a educação em sua estreita relação com a sociedade no processo de desenvolvimento histórico. Com efeito, a educação é inerente à sociedade, originando-se do mesmo processo que deu origem ao homem. Desde que o homem é homem ele vive em sociedade e se desenvolve pela mediação da educação. A humanidade se constituiu a partir do momento em que determinada espécie natural de seres vivos se destacou da natureza e, em lugar de sobreviver adaptando-se a ela, necessita, para continuar existindo, adaptar a natureza a si. Dessa forma, o homem tem de se apropriar da natureza e transformá-la de acordo com suas necessidades, sem o que ele perece. Diferentemente, portanto, dos animais que têm a sua existência garantida pela natureza bastando-Ihes adaptar-se a ela, 0 homem necessita produzir sua própria existência. Ora, a produção da existência implica o desenvolvimento de formas e conteúdos cuja validade é estabelecida pela experiência, o que configura um verdadeiro processo de aprendizagem. Assim, enquanto os elementos não validados pela experiência são afastados, aqueles cuja eficácia a experiência corrobora necessitam ser preservados e transmitidos às novas gerações no interesse da continuidade da espécie.

Nas comunidades primitivas a educação coincide totalmente com o fenômeno acima descrito. Os homens se apropriam coletivamente dos meios de produção da existência e nesse processo se educam e educam as novas gerações. Nas sociedades antigas e medievais, com a apropriação privada da terra, então o principal meio de produção, surge uma classe que vive do trabalho alheio e, em consequência, desenvolve-se um tipo de educação diferenciada destinada aos grupos dominantes cuja função é preencher o tempo livre de forma digna ("otium cum dignitate"). Aí está a origem da palavra escola (do grego skolé= lazer, tempo 
livro, ócio e, por extensão, ocupação dos homens que dispõem de lazer; estudo) assim como de ginásio que, em grego significa local dos exercícios físicos, local dos jogos.

Essa educação diferenciada, desenvolvida de forma sistemática através de instituições específicas era, portanto, reservada à minoria, à elite. A maioria, isto é, aqueles que, através do trabalho garantiam a produção da existência de si mesmos assim como de seus senhores, continuava a ser educada de maneira assistemática pela experiência de vida cujo centro era 0 trabalho. Nesse contexto, a forma escolar de educação era uma forma secundária que se contrapunha como não-trabalho à forma de educação dominante determinada pelo trabalho.

$\mathrm{Na}$ sociedade moderna (ou capitalista, ou burguesa) a classe dominante (burguesia) detém a propriedade privada dos meios de produção (condições e instrumentos de trabalho convertidos em capital) obtida pela expropriação dos produtores. Entretanto, diferentemente dos senhores feudais (nobreza) a burguesia não pode ser considerada uma classe ociosa. Ao contrário, é uma classe empreendedora, compelida a revolucionar constantemente as relações de produção, portanto, toda a sociedade. Oriunda das atividades mercantis que permitiram um primeiro nível de acumulação de capital, a burguesia tende a converter todos os produtos do trabalho em valor-de-troca, cuja mais-valia é incorporada ao capital que se amplia insaciavelmente.

Nesse processo, o campo é subordinado à cidade e a agricultura à indústria, que realiza a conversão da ciência, potência espiritual, em potência material. $O$ predomínio da cidade e da indústria sobre o campo e a agricultura tende a se generalizar e a esse processo corresponde a exigência de generalização da escola. Assim, não é por acaso que a constituição da sociedade burguesa trouxe consigo a bandeira da escolarização universal e obrigatória. Com efeito, a vida urbana, cuja base é a indústria, se rege por normas que ultrapassam o direito natural, sendo codificadas no chamado direito positivo que, dado o seu caráter 
convencional, formalizado, sistemático, se expressa em termos escritos. Daí a incorporação, na vida da cidade, da expressão escrita de tal modo que não se pode participar plenamente dela sem o domínio dessa forma de linguagem. Por isso, para ser cidadão, isto é, para participar ativamente da vida da cidade, do mesmo modo que para ser trabalhador produtivo, é necessário o ingresso na cultura letrada. E sendo a cultura letrada um processo formalizado, sistemático, só pode ser atingida por meio de um processo educativo também sistemático. $\mathrm{E}$ a escola é, por sua vez, a instituição que propicia de forma sistemática o acesso à cultura letrada reclamado pelos membros da sociedade moderna.

Nesse contexto, a forma principal e dominante de educação passa a ser a educação escolarizada. Frente a ela a educação difusa e assistemática, embora não deixando de existir, perde relevância e passa a ser aferida pela determinação da forma escolarizada. A educação escolar representa, pois, em relação à educação extraescolar, a forma mais desenvolvida, mais avançada. $\mathrm{E}$ como é a partir do mais desenvolvido que se pode compreender o menos desenvolvido e não o contrário, é a partir da escola que é possível compreender a educação em geral e não o contrário. De fato, isso fica evidente na própria maneira como nos expressamos. Com efeito, a educação escolar é simplesmente entendida como a educação. Já as outras modalidades são sempre definidas pela via negativa. Referimo-nos a elas lançando mão de denominações como educação não escolar, não formal, informal, extraescolar. Portanto, a referência de análise, isto é, o parâmetro para se considerar as outras modalidades de educação, é a própria educação escolar.

Pode-se dizer, à guisa de síntese, que, ao deslocamento do eixo do processo produtivo do campo para a cidade, da agricultura para a indústria e ao deslocamento do eixo do processo cultural do saber espontâneo, assistemático para o saber metódico, sistemático, científico, correspondeu o deslocamento do eixo do processo educativo de formas difusas, identificadas com o próprio processo de produção da existência, para formas específicas e institucionalizadas, identificadas com a escola. E as necessidades postas por 
essa nova forma de organização da sociedade conduziram a uma nova forma de estruturação do currículo, isto é, dos conteúdos do ensino.

Assim, são as necessidades sociais que determinam o conteúdo, isto é, o currículo da educação escolar em todos os seus níveis e modalidades.

\section{Os saberes necessários à organização dos currículos formativos}

Já vimos que a origem da educação se confunde com as origens do próprio

homem. E porque a educação é um fenômeno específico dos seres humanos, a compreensão de sua natureza passa pela compreensão da natureza humana. E a natureza humana não é dada ao homem, mas é por ele próprio produzida no mesmo ato em que ele produz sua existência ao transformar a natureza de acordo com suas necessidades.

Portanto, se para sobreviver o homem necessita extrair da natureza, ativa e intencionalmente, os meios de sua subsistência, ao fazer isso ele inicia o processo de transformação do mundo natural criando um mundo humano (o mundo da cultura). Esse processo implica, primordialmente, a garantia da subsistência material com a consequente produção, em escalas cada vez mais amplas e complexas, de bens materiais (trabalho material).

Entretanto, para produzir materialmente o homem necessita antecipar em ideias os objetivos da ação, o que significa que ele representa mentalmente os objetivos reais. Essa representação inclui o aspecto de conhecimento das propriedades do mundo real (ciência), de valorização (ética) e de simbolização (arte). Trata-se aqui do trabalho não material, isto é, a produção de ideias, conceitos, valores, símbolos, hábitos, atitudes, habilidades. Numa palavra, tratase da produção do saber, seja do saber sobre a natureza, seja do saber sobre a cultura, isto é, o conjunto da produção humana. Obviamente a educação se situa nessa categoria do trabalho não material. 
Cabe, porém, considerar que, se a educação, pertencendo ao âmbito da produção não material, tem a ver com ideias, conceitos, valores, símbolos, hábitos, atitudes, habilidades, tais elementos não Ihe interessam em si mesmos, como algo exterior ao homem.

Nessa forma, isto é, considerados em si mesmos, como algo exterior ao homem, esses elementos constituem o objeto de preocupação das chamadas ciências humanas em contraposição às ciências da natureza. Diferentemente, do ponto de vista da educação, ou seja, da perspectiva da pedagogia entendida como ciência da educação, esses elementos interessam enquanto é necessário que os homens os assimilem, tendo em vista a constituição de algo como uma segunda natureza. Com efeito, o que não é garantido pela natureza tem que ser produzido historicamente pelos homens; e aí se incluem os próprios homens.

Podemos, pois, dizer que a natureza humana não é dada ao homem, mas é por ele próprio produzida sobre a base da natureza biofísica. Consequentemente, "o trabalho educativo é o ato de produzir, direta e intencionalmente, em cada indivíduo singular, a humanidade que é produzida histórica e coletivamente pelo conjunto dos homens" (SAVIANI, 2013, p. 13).

Em suma, os diferentes tipos de saber, do ponto de vista da educação, não interessam em si mesmos. Eles interessam, sim, mas enquanto elementos que os indivíduos da espécie humana necessitam assimilar para que se tornem humanos, isto é, para que integrem o gênero humano. Isto porque o homem não se faz homem naturalmente; ele não nasce sabendo ser homem, vale dizer, ele não nasce sabendo sentir, pensar, avaliar, agir. Para saber pensar e sentir, para saber querer, agir ou avaliar, é preciso aprender, o que implica o trabalho educativo. Em verdade, deixado em condições puramente naturais, afastado de todo e qualquer convívio humano, o indivíduo não chega a ser homem. Ou ele perece - hipótese mais provável - ou não ascenderá à condição humana, o que está evidenciado no livro "As crianças selvagens", construído a partir da memória 
e relatório de Jean Itard sobre Victor de L'Aveyron, o menino selvagem (MALSON, 1967) que sobreviveu fora do convívio humano, mas não atingiu a condição humana, o que só veio a acontecer por meio do trabalho educativo realizado por Itard.

Consequentemente, o saber que diretamente interessa à educação é aquele referido ao processo de aprendizagem, voltado à produção do resultado do trabalho educativo. Entretanto, para chegar a esse resultado a educação tem que partir, tem que tomar como referência, como matéria-prima de sua atividade, o saber objetivo produzido historicamente.

O fenômeno educativo manifesta-se, pois, desde a origem do homem pelo desenvolvimento de processos educativos inicialmente coincidentes com 0 próprio ato de viver, os quais foram se diferenciando progressivamente até atingir um caráter institucionalizado cuja forma mais conspícua se revela no surgimento da escola. Esta aparece de início como manifestação secundária e derivada dos processos educativos mais gerais, mas vai se transformando lentamente ao longo da história até erigir-se na forma principal e dominante de educação. Esta passagem da escola à forma dominante de educação coincide com a etapa histórica em que as relações sociais passaram a prevalecer sobre as relações naturais estabelecendo-se o primado do mundo da cultura (o mundo produzido pelo homem) sobre o mundo da natureza. Em consequência, o saber metódico, sistemático, científico, elaborado passa a predominar sobre o saber espontâneo, "natural", assistemático, resultando daí que a especificidade da educação passa a ser determinada pela forma escolar. A etapa histórica em referência - que ainda não se esgotou - corresponde ao surgimento e desenvolvimento da sociedade capitalista cujas contradições vão colocando de forma cada vez mais intensa a necessidade de sua superação.

Levando em conta os contornos assumidos pelo fenômeno educativo no contexto da sociedade atual, tentemos identificar os principais tipos de saber nele implicados. 


\section{4. $O$ processo educativo: os saberes que o configuram}

O processo educativo é um fenômeno complexo, todos reconhecem. Tentando apreendê-lo na sua manifestação concreta na sociedade atual, a observação imediata nos coloca diante de um universo empírico bastante heterogêneo seja quanto às formas de organização e efetivação, seja quanto às representações que dele fazem seus agentes. Nesse contexto, os saberes nele envolvidos também se revestem da aparência de um caos irredutível. Procedendo analiticamente e procurando identificar certas características comuns que possam constituir as notas distintivas do fenômeno educativo, chegamos a uma categorização dos saberes que, com uma boa margem de consenso, se entende que todo educador deve dominar e, por consequência, devem integrar 0 processo de sua formação. São eles:

\subsection{O saber atitudinal}

Esta categoria compreende o domínio dos comportamentos e vivências consideradas adequadas ao trabalho educativo. Abrange atitudes e posturas inerentes ao papel atribuído ao educador, tais como disciplina, pontualidade, coerência, clareza, justiça e equidade, diálogo, respeito às pessoas dos educandos, atenção às suas dificuldades etc. Trata-se de competências que se prendem à identidade e conformam a personalidade do educador, mas que são objeto de formação tanto por processos espontâneos como deliberados e sistemáticos.

\subsection{O saber crítico-contextual}

Trata-se do saber relativo à compreensão das condições sócio históricas que determinam a tarefa educativa. Entende-se que os educandos devam ser preparados para integrar a vida da sociedade em que estão inseridos de modo a desempenhar nela determinados papéis de forma ativa e, o quanto possível, inovadora. Espera-se, assim, que o educador saiba compreender o movimento da sociedade identificando suas características básicas e as tendências de sua transformação de modo a detectar as necessidades presentes e futuras a serem atendidas pelo processo educativo sob sua responsabilidade. A formação do educador envolverá, 
pois, a exigência de compreensão do contexto a partir do qual e para o qual se desenvolve o trabalho educativo, traduzida aqui na categoria do saber crítico-contextual.

\subsection{Os saberes específicos}

Nesse âmbito incluem-se os saberes correspondentes às disciplinas em que se recorta o conhecimento socialmente produzido e que integram os currículos escolares. Trata-se dos conhecimentos oriundos das ciências da natureza, das ciências humanas, das artes ou das técnicas, obviamente considerados, como se assinalou, não em si mesmos, mas enquanto elementos educativos, isto é, que precisam ser assimilados pelos educandos em situações específicas. Sob esse ponto de vista não é lícito ao educador ignorar esses saberes os quais devem, em consequência, integrar o processo de sua formação.

\subsection{O saber pedagógico}

Aqui se incluem os conhecimentos produzidos pelas ciências da educação e sintetizados nas teorias educacionais visando a articular os fundamentos da educação com as orientações que se imprimem ao trabalho educativo. Em verdade esse tipo de saber fornece a base de construção da perspectiva especificamente educativa a partir da qual se define a identidade do educador como um profissional distinto dos demais profissionais, estejam eles ligados ou não ao campo educacional.

\subsection{O saber didático-curricular}

Sob essa categoria compreendem-se os conhecimentos relativos às formas de organização e realização da atividade educativa no âmbito da relação educador-educando. É, em sentido mais específico, o domínio do saber fazer. Implica não apenas os procedimentos técnico-metodológicos, mas a dinâmica do trabalho pedagógico enquanto uma estrutura articulada de agentes, conteúdos, instrumentos e procedimentos que se movimentam no espaço e tempo pedagógicos visando atingir objetivos intencionalmente formulados.

Eis aí, em suma, o conjunto dos saberes que, em princípio, todo educador deve dominar e que, por isso integrarão o processo de sua formação e orientarão a organização e funcionamento dos currículos escolares. 


\section{As formas e os agentes do saber educativo}

Os saberes arrolados no item anterior foram categorizados pelo ângulo dos conteúdos de que são portadores. Entretanto, o eixo comum relativo às formas em que se constituem e se expressam esses saberes se manifesta na diferença entre "sofia" (o saber decorrente da experiência de vida) e "episteme" (o saber decorrente de processos sistemáticos de construção de conhecimentos). Como se sabe, o vocábulo grego "sofia" significa a sabedoria fundada numa longa experiência de vida. É nesse sentido que se diz que os velhos são sábios e que os jovens devem ouvir e seguir seus conselhos. Já "episteme" significa ciência, isto é, o conhecimento metódico e sistematizado. Consequentemente, se do ponto de vista da "sofia" um velho é sempre mais sábio do que um jovem, do ponto de vista da "episteme" um jovem pode ser mais sábio do que um velho.

Considerando a partir do ponto de vista da forma os saberes implicados na formação do educador, é possível constatar que a forma "sofia" e também a forma "episteme" atravessam indistintamente os diferentes tipos de saber, ainda que com ênfases diferenciadas. Assim, se no caso do "saber atitudinal" tende a predominar a experiência prática e nos casos dos "saberes específicos" e do "saber pedagógico" prevalecem os processos sistemáticos, ficando em posição intermediária os saberes "crítico-contextual" e "didático-curricular", é certo que a forma "episteme" marca também o saber atitudinal assim como a forma "sofia" não está ausente do modo como o educador apreende os saberes específicos e o saber pedagógico. Com efeito, as atitudes, à medida que se configuram como saber, implicam necessariamente certo grau de sistematização assim como a experiência de vida tem um peso que não pode ser desconsiderado na forma como se constroem os saberes específicos e o saber pedagógico.

Observa-se mesmo que o grau de participação de cada uma dessas formas varia de acordo com a variação das teorias educacionais. Assim, a teoria da educação tradicional tende a situar o saber atitudinal no âmbito das condições 
organizacionais do trabalho pedagógico trazendo para o centro dos processos sistemáticos os conteúdos de conhecimento e as formas de sua transmissão. Já a pedagogia nova traz para o próprio núcleo do processo educativo a formação de atitudes buscando sistematizar a experiência dos educandos como elemento de reconstrução dos próprios conhecimentos socialmente elaborados. Por sua vez, a pedagogia tecnicista coloca no centro do trabalho educativo o saber didático-curricular cuja operacionalização, a mais detalhada possível, é considerada garantia dos objetivos que se busca atingir.

Tendo em vista o exposto não nos pareceu pertinente em nossa categorização falar em "saberes da experiência" como um tipo de saber ao lado dos demais, como o fizeram TARDIF, LESSARD e LAHAYE (1991, p. 219-221). Isto porque, a nosso ver, não se trata aí de um conteúdo diferenciado dos demais, mas de uma forma (a forma sofia) que pode estar referida indistintamente aos diferentes tipos de saber.

Outra determinação que cumpre assinalar diz respeito ao fato de que no tratamento dos diferentes tipos de saber cabe levar em conta não apenas o grau efetivo ou potencial de seu domínio por parte do educador, mas também o domínio potencial assim como efetivo dos referidos saberes por parte do educando. Com efeito, ainda que integrem o trabalho educativo múltiplos agentes, o núcleo fundamental constitutivo do ato educativo é dado na relação educador-educando. Já no ponto de partida da relação pedagógica os educandos se apresentam como portadores não apenas potenciais, mas também reais, de saberes relativos às atitudes, à compreensão do contexto, a conhecimentos específicos, às teorias educacionais e às questões didáticocurriculares, saberes esses que devem ser atentamente levados em conta pelo educador e, portanto, devem integrar a sua formação.

\section{A relação educativa como prática social mediadora da prática social global}


$\mathrm{Na}$ consideração dos saberes envolvidos na educação cumpre levar em conta que eles implicam igualmente educadores e educandos os quais se põem numa relação prática determinada socialmente como momento da prática social global tendo nesta, portanto, o seu ponto de partida e seu ponto de chegada. Como tal, a prática educativa assume o caráter de mediação no seio da prática social não se justificando, pois, por si mesma, mas pelos efeitos que produz no âmbito da prática social global por ela mediada. Sua eficácia é aferida, portanto, pelas mudanças qualitativas que provoca na prática social. Os agentes educativos são, então, antes como depois, mas também durante o ato educativo, agentes sociais cuja qualidade se modifica por efeito do trabalho pedagógico.

Essa peculiaridade da prática educativa põe em posições diferenciadas os dois polos da relação pedagógica: o educador e o educando (SAVIANI, 2012a, pp.7080). No ponto de partida o educador, de um lado, e o educando, de outro, se encontram em níveis diferentes de compreensão e, portanto, de inserção na prática social. Enquanto o educador tem uma compreensão sintética, ainda que precária, a compreensão do educando é de caráter sincrético. A compreensão do educador é sintética porque implica certa articulação dos saberes que detém relativamente à prática social, o que lhe permite dispor a relação educativa como um processo cujo ponto de chegada é percebido com razoável clareza. Tal síntese, porém, é precária uma vez que, por mais articulados que sejam os saberes que domina, a inserção de sua própria prática pedagógica como uma dimensão da prática social envolve uma antecipação do que lhe será possível fazer com educandos cujos níveis de compreensão ele não pode conhecer, no ponto de partida, senão de forma precária. Por seu lado, a compreensão do educando é sincrética uma vez que, por mais saberes que detenha, sua própria condição de educando implica uma impossibilidade, no ponto de partida, de articulação da experiência pedagógica com a prática social de que participa.

Considerando a relação educativa agora sob o ângulo do ponto de chegada, que é a própria prática social, verifica-se que neste ponto, ao mesmo tempo em que 
o educando ascende ao nível sintético onde, por suposto, já se encontrava o educador no ponto de partida, reduz-se a precariedade da síntese do educador, cuja compreensão se torna mais orgânica. Essa elevação do educando ao nível do educador é essencial para se compreender a especificidade da relação pedagógica. É, com efeito, pela mediação analítica levada a cabo na relação educativa que se dá a passagem da síncrese à síntese. Em consequência, no ponto de chegada manifesta-se no educando a capacidade de expressar uma compreensão da prática em termos tão elaborados quanto era possível ao educador no ponto de partida.

Por meio do referido processo, a compreensão da prática social passa por uma alteração qualitativa. Por isso, a prática social posta no ponto de partida e aquela do ponto de chegada são e não são a mesma.

Por um lado, trata-se da mesma prática, uma vez que é a prática social que constitui ao mesmo tempo o suporte e o contexto, o pressuposto e o alvo, 0 fundamento e a finalidade da prática pedagógica. Em suma, trata-se da própria prática social global em cujo interior se situa a educação.

Por outro lado, não se trata da mesma prática, se considerarmos que o modo de nos situarmos em seu interior se alterou qualitativamente pela mediação da ação pedagógica; e já que somos, enquanto agentes sociais, elementos objetivamente constitutivos da prática social, é lícito afirmar que a própria prática se alterou qualitativamente.

Por conseguinte, é preciso ficar claro que os saberes mobilizados pelo educador se articulam em função do objetivo propriamente pedagógico, isto é, o desenvolvimento do educando, que significa a transformação qualitativa de seu modo de inserção na prática social. Eis porque se afirmou antes que os saberes historicamente produzidos, do ponto de vista da educação não interessam por si mesmos, mas enquanto elementos por meio dos quais cada indivíduo singular sintetiza, em si próprio, a humanidade que é produzida histórica e coletivamente 
pelo conjunto dos homens.

\section{A determinação pela educação}

Se os conhecimentos produzidos socialmente, no que se refere à educação, não interessam por si mesmos e se o conjunto dos saberes mobilizados pelo educador se articulam em função do objetivo propriamente pedagógico que se liga ao desenvolvimento do educando, então não são os saberes, enquanto tais, que determinam a construção dos currículos escolares. Ao contrário disso, são os objetivos educativos que determinam a seleção dos saberes que deverão compor a organização dos currículos.

No primeiro caso, ou seja, se se entender que são os conhecimentos socialmente produzidos que determinam a organização curricular, nós teríamos os saberes já constituídos externamente à educação e por critérios também externos a ela, saberes estes a partir dos quais se determinaria o conteúdo do ensino e, portanto, o currículo.

No segundo caso, isto é, considerando-se os objetivos educacionais como determinantes do currículo, nós partimos da situação educacional e, por critérios dela derivados, determinam-se os conteúdos do trabalho educativo. A partir daí cabe definir, entre os saberes disponíveis socialmente, os conhecimentos que devem integrar os currículos escolares selecionando-se, em consequência, os aspectos considerados relevantes para a educação e estabelecendo a forma e o lugar que vão ocupar nos currículos em geral e, especificamente, nos cursos de formação dos professores.

A questão posta é análoga àquela relativa à pesquisa educacional que analisei em 1976 (SAVIANI, 2007, pp. 113-114). Aí eu me referia à relação entre as chamadas ciências da educação e a educação propriamente, formando dois tipos de circuito ilustrados por meio do seguinte gráfico: 
A

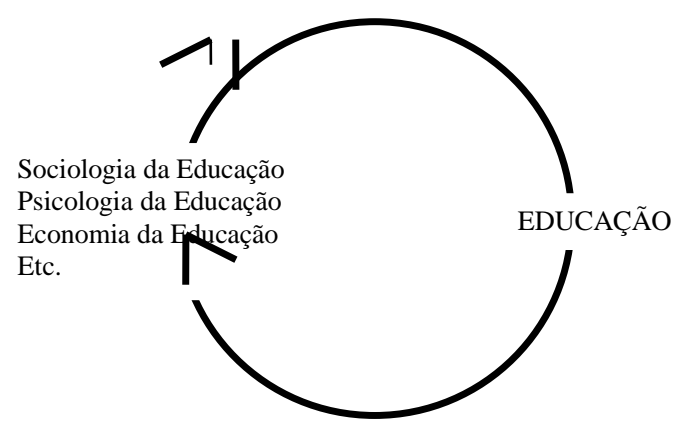

B

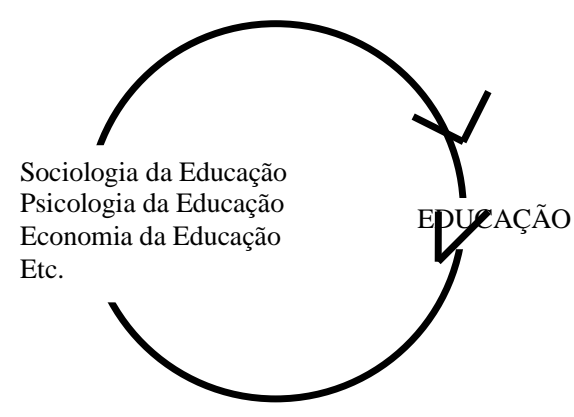

O gráfico permite visualizar as duas situações. Na situação "A", a educação é ponto de passagem: ela está descentrada. $O$ ponto de partida e o ponto de chegada estão alhures. Isto significa que as pesquisas e, portanto, os saberes produzidos no âmbito da sociologia da educação, da psicologia da educação, etc. circunscrevem a educação como seu objeto, encarando-a como um fenômeno sociológico, psicológico, etc., o qual é visto, consequentemente, à luz das teorizações específicas a partir de cuja estrutura conceptual são mobilizadas as hipóteses explicativas do aludido fenômeno. O processo educativo é encarado, pois, como campo de teste das hipóteses que, uma vez verificadas, redundarão no enriquecimento do acervo teórico das disciplinas específicas referidas.

A situação "B" representa a inversão do circuito. A educação, enquanto ponto de partida e de chegada, torna-se o centro das preocupações. Note-se que ocorre agora uma profunda mudança de projeto. Em vez de se considerar a educação a partir de critérios psicológicos, sociológicos, econômicos, etc., são as contribuições das diferentes áreas que serão avaliadas a partir da problemática educacional. O processo educativo erige-se, assim, em critério, o que significa dizer que a incorporação desse ou daquele aspecto do acervo teórico constituído pelos saberes socialmente disponíveis dependerá da natureza dos problemas enfrentados pelos educadores. 
Aplicando essa reflexão ao tema da relação entre os saberes e a organização curricular, vê-se que na situação "A" são os saberes que determinam a organização curricular; na situação "B", inversamente, é o problema da educação com a respectiva organização curricular que determina os saberes ou, mais precisamente, é o problema da educação que determina a escolha dos saberes que entrarão na composição dos currículos formativos.

Enfim, acredita-se que, tomando o processo educativo como ponto de partida e ponto de chegada, será possível construir currículos que incorporem as contribuições correspondentes aos diferentes saberes em que se recorta o conhecimento socialmente produzido. A problemática educativa será, pois, a referência para se determinar o conteúdo dos currículos tanto no que se refere à formação de educadores quanto no que diz respeito à organização do ensino nos diferentes níveis e modalidades educativas. Dessa forma o trabalho educativo estará capacitado a responder adequadamente aos problemas postos pela prática social que se desenvolve na sociedade contemporânea.

\section{A base nacional comum curricular}

Dispostos os elementos que nos permitem compreender as relações entre educação escolar, currículo e sociedade situando o problema dos saberes necessários à formação de indivíduos humanos desenvolvidos em sintonia com o máximo grau de desenvolvimento das objetivações humanas nas condições atuais, estamos em condição de abordar o problema da base nacional comum curricular referente ao conjunto da educação básica.

A noção de uma base comum nacional emergiu como uma ideia-força do movimento pela reformulação dos cursos de formação de educadores. Esse movimento começou a se articular no final dos anos de 1970, materializando-se na I Conferência Brasileira de Educação realizada em São Paulo nos dias 31 de 
março, $1^{\circ}$ e 2 de abril de 1980, ocasião em que foi criado o "Comitê Pró Participação na Reformulação dos Cursos de Pedagogia e Licenciatura" que se transformou, em 1983, na Comissão Nacional pela Reformulação dos Cursos de Formação de Educadores" (CONARCFE). Esta, por sua vez, deu origem, em 1990, à atual ANFOPE (Associação Nacional pela Formação dos Profissionais da Educação). Nos eventos realizados pelo referido movimento do campo educacional a ideia da "base comum nacional" foi sendo explicitada mais pela negação do que pela afirmação. Assim, foi se fixando o entendimento segundo o qual a referida ideia não coincide com a parte comum do currículo, nem com o currículo mínimo sendo, antes, um princípio a inspirar e orientar a organização dos cursos de formação de educadores em todo o país. Como tal, seu conteúdo não poderia ser fixado por um órgão de governo, por um intelectual de destaque e nem mesmo por uma assembleia de educadores, mas deveria fluir das análises, dos debates e das experiências encetadas possibilitando, no médio prazo, chegar a um consenso em torno dos aspectos fundamentais que devem basear a formação dos profissionais da educação.

Observe-se que a Lei de Diretrizes e Bases da Educação Nacional, de 20 de dezembro de 1996, incorporou essa ideia ao definir, no Art. 26, que "os currículos do ensino fundamental e médio devem ter uma base nacional comum"; e, no Art. 64, que a formação dos profissionais da educação "será feita em cursos de graduação em pedagogia ou em nível de pós-graduação, a critério da instituição de ensino, garantida, nesta formação, a base comum nacional" sem, entretanto, explicitar o significado dessa expressão. Contudo, a sequência do artigo 26 , ao afirmar que a base nacional comum deve "ser complementada, em cada sistema de ensino e estabelecimento escolar, por uma parte diversificada", respalda a interpretação de que a "base nacional comum" coincide com a parte comum do currículo, conforme a legislação anterior. Com efeito, a Lei 5.692, de 11 de agosto de 1971 , definiu, no Art. $4^{\circ}$, que "os currículos do ensino de $1^{\circ}$ e $2^{\circ}$ graus terão um núcleo comum, obrigatório em âmbito nacional, e uma parte diversificada...". 
Ao que parece, o encaminhamento da base comum nacional curricular, nos termos da LDB, foi equacionado por meio da elaboração e aprovação, pelo Conselho Nacional de Educação, das Diretrizes Curriculares Nacionais relativas aos vários níveis e modalidades de ensino. É isso, com efeito, que flui do disposto no Inciso IV do Art. 9o que atribui à União o encargo de estabelecer "competências e diretrizes para a educação infantil, o ensino fundamental e o ensino médio, que nortearão currículos e seus conteúdos mínimos, de modo a assegurar formação básica comum". E o próprio documento elaborado pelo MEC sobre a "base nacional comum curricular" se reporta às Diretrizes Curriculares Nacionais definidas pelo Conselho Nacional de Educação, que continuam em vigor. Emerge, então, inevitavelmente, a seguinte pergunta: se a base comum já se encontra definida por meio das diretrizes curriculares nacionais, que são mantidas, qual o sentido desse empenho em torno da elaboração e aprovação de uma nova norma relativa à "base nacional comum curricular"?

Considerando a centralidade que assumiu a questão da avaliação aferida por meio de testes globais padronizados na organização da educação nacional e tendo em vista a menção a outros países, com destaque para os Estados Unidos tomados como referência para essa iniciativa de elaborar a "base comum nacional curricular" no Brasil, tudo indica que a função dessa nova norma é ajustar o funcionamento da educação brasileira aos parâmetros das avaliações gerais padronizadas. Essa circunstância coloca em evidência as limitações dessa tentativa, pois, como já advertimos, essa subordinação de toda a organização e funcionamento da educação nacional à referida concepção de avaliação implica numa grande distorção do ponto de vista pedagógico (SAVIANI, 2012, p. 316-317), entendimento que veio a ser reforçado pela ampla e contundente crítica efetuada por Diane Ravitch (2011) sobre o sistema americano, que está sendo tomado como modelo pelo Brasil.

Diante das limitações apontadas apresento, a seguir, para subsidiar o debate sobre o tema da "base nacional comum curricular", outro encaminhamento da questão. 
Para identificar os conteúdos básicos que devem compor os currículos de toda a educação básica, desde a educação infantil até o ensino médio, proponho que se tome como referência o conceito do trabalho como princípio educativo. De modo geral, podemos considerar que esse conceito compreende três significados: Num primeiro sentido, o trabalho é princípio educativo na medida em que determina, pelo grau de desenvolvimento social atingido historicamente, o modo de ser da educação em seu conjunto. Assim entendido, aos modos de produção correspondem modos distintos de educar com uma correspondente forma dominante de educação. Em um segundo sentido, o trabalho é princípio educativo na medida em que coloca exigências específicas que o processo educativo deve preencher, em vista da participação direta dos membros da sociedade no trabalho socialmente produtivo. Finalmente, o trabalho é princípio educativo, num terceiro sentido, à medida que determina a educação como modalidade específica e diferenciada de trabalho: o trabalho pedagógico.

Para a definição da base curricular relativa à educação infantil devemos tomar como referência o aporte da Psicologia Histórico-Cultural que indica como referência para a identificação do conteúdo e forma do desenvolvimento do ensino a atividade-guia própria de cada período da vida dos indivíduos.

Partindo da vida intrauterina com a transição pós-natal nós temos, no primeiro ano de vida, a atividade emocional direta com o adulto como atividade-guia. Nesse momento o conteúdo da educação envolve a compreensão das características próprias da vida uterina e pós-natal em que a estabilidade da formação do bebê é diretamente dependente da comunicação emocional direta com o adulto (mãe-pai, cuidador...). Evidencia-se, assim, a natureza tipicamente social do bebê e a determinação de seu desenvolvimento pelas condições educacionais em que o referido desenvolvimento ocorre.

$\mathrm{Na}$ etapa seguinte, correspondente ao segundo e terceiro anos de vida, a atividade-guia é a atividade objetal manipulatória. Nessa fase já se trata de 
organizar intencionalmente os conteúdos, meios e procedimentos, guiados pela atividade objetal manipulatória para assegurar um processo de ensino que viabilize a aprendizagem da criança nos seus primeiros anos de vida.

Passa-se, em seguida, à idade pré-escolar ( $4^{\circ}$ e $5^{\circ}$ anos) na qual a atividadeguia é a brincadeira de papeis sociais. Aqui já se trata de organizar o ensino de maneira a possibilitar à criança a apropriação do acervo cultural da humanidade superando-se as concepções naturalizantes do ato de brincar. Dá-se, assim, a transição da Educação Infantil para o Ensino Fundamental. Neste a atividadeguia é a atividade de estudo.

Tomando como referência as reflexões de Gramsci sobre o trabalho como princípio educativo da escola unitária, esbocei, em trabalho anterior (SAVIANI, 2014, p. 66-74), a conformação do sistema de ensino tendo em vista as condições da sociedade brasileira atual. Levando em conta que o entendimento gramsciano da escola unitária corresponde à fase que hoje, no Brasil, é definida como a educação básica, especificamente nos níveis fundamental e médio retomo, agora, com eventuais ajustes, o referido esboço.

Considerando o primeiro sentido do trabalho como princípio educativo, vemos que o modo como está organizada a sociedade atual é a referência para a organização do ensino fundamental. O nível de desenvolvimento atingido pela sociedade contemporânea coloca a exigência de um acervo mínimo de conhecimentos sistemáticos sem o que não se pode ser cidadão, isto é, não se pode participar ativamente da vida da sociedade.

O acervo em referência inclui a linguagem escrita e a matemática, já incorporadas na vida da sociedade atual; as ciências da natureza, cujos elementos básicos relativos ao conhecimento das leis que regem a natureza são necessários para se compreender as transformações operadas pela ação do homem sobre o meio ambiente; e as ciências da sociedade, pelas quais se pode compreender as relações entre os homens, as formas como eles se organizam, 
as instituições que criam e as regras de convivência que estabelecem, com a consequente definição de direitos e deveres. O último componente (ciências da sociedade) corresponde, na atual estrutura, aos conteúdos de história e geografia. Eis aí como se configura o currículo da escola elementar, complementado pela Educação Artística e Educação Física. A primeira, em continuidade com as atividades já desenvolvidas na Educação Infantil, permite às crianças não apenas a objetivação de sua expressão criativa, mas sua iniciação e familiarização com as produções artísticas mais desenvolvidas da humanidade. A segunda permitirá às crianças progressivamente assumirem plenamente sua corporeidade adquirindo controle do próprio corpo tanto em relação ao desenvolvimento pleno dos movimentos corporais como, em sentido inverso, desenvolvendo a capacidade de contenção do movimento físico exigida pela disciplina necessária à realização do trabalho intelectual.

A base em que se assenta a estrutura do ensino fundamental é o princípio educativo do trabalho. O estudo das ciências naturais, assinala Gramsci, visa introduzir as crianças na "societas rerum" e pelas ciências sociais elas são introduzidas na "societas hominum":

O conceito e o fato do trabalho (da atividade teórico-prática) é o princípio educativo imanente à escola elementar, já que a ordem social e estatal (direitos e deveres) é introduzida e identificada na ordem natural pelo trabalho. O conceito do equilíbrio entre ordem social e ordem natural sobre o fundamento do trabalho, da atividade teórico-prática do homem, cria os primeiros elementos de uma intuição do mundo liberta de toda magia ou bruxaria, e fornece o ponto de partida para o posterior desenvolvimento de uma concepção histórico-dialética do mundo... (GRAMSCI, 1975, vol. III, p. 1541; na edição brasileira, 1968, p. 130).

Uma vez que o princípio do trabalho é imanente à escola elementar, isto significa que no ensino fundamental a relação entre trabalho e educação é implícita e indireta. Ou seja, o trabalho orienta e determina o caráter do currículo escolar em função da incorporação dessas exigências na vida da sociedade. A escola elementar não precisa, então, fazer referência direta ao processo de trabalho. Aprender a ler, escrever e contar e dominar os rudimentos das ciências naturais e das ciências sociais constituem pré-requisitos para 
compreender o mundo em que se vive, inclusive para entender a própria incorporação pelo trabalho dos conhecimentos científicos no âmbito da vida e da sociedade.

Se no ensino fundamental a relação é implícita e indireta, no ensino médio a relação entre educação e trabalho, entre o conhecimento e a atividade prática deverá ser tratada de maneira explícita e direta. Intervém aqui, pois, o segundo sentido do conceito de trabalho como princípio educativo. O papel fundamental da escola de nível médio será, então, o de recuperar essa relação entre o conhecimento e a prática do trabalho.

Assim, no ensino médio já não basta dominar os elementos básicos e gerais do conhecimento que resultam e ao mesmo tempo contribuem para o processo de trabalho na sociedade. Trata-se, agora, de explicitar como o conhecimento (objeto específico do processo de ensino), isto é, como a ciência, potência espiritual, se converte em potência material no processo de produção. Tal explicitação deve envolver o domínio não apenas teórico, mas também prático sobre o modo como o saber se articula com o processo produtivo.

Um exemplo de como a atividade prática, manual, pode contribuir para explicitar a relação entre ciência e produção é a transformação da madeira e do metal pelo trabalho humano (Cf. PISTRAK, p. 55-56). O trabalho com a madeira e o metal tem imenso valor educativo, pois envolve não apenas a produção da maioria dos objetos que compõem o processo produtivo moderno, mas também a produção de instrumentos com os quais esses objetos são produzidos. No trabalho prático com madeira e metal, aplicando os fundamentos de diversificadas técnicas de produção, pode-se compreender como a ciência é aplicada ao processo produtivo; pode-se perceber como as leis da física e da química operam para vencer a resistência dos materiais e gerar novos produtos. Faz-se, assim, a articulação da prática com o conhecimento teórico. 
O ensino médio envolverá, pois, o recurso às oficinas nas quais os alunos manipulam os processos práticos básicos da produção; mas não se trata de reproduzir na escola a especialização que ocorre no processo produtivo. $O$ horizonte que deve nortear a organização do ensino médio é o de propiciar aos alunos o domínio dos fundamentos das técnicas diversificadas utilizadas na produção, e não o mero adestramento em técnicas produtivas. Não a formação de técnicos especializados, mas de politécnicos.

Politecnia significa, aqui, especialização como domínio dos fundamentos científicos das diferentes técnicas utilizadas na produção moderna. Nessa perspectiva a educação de nível médio tratará de se concentrar nas modalidades fundamentais que dão base à multiplicidade de processos e técnicas de produção existentes.

Esta é uma concepção radicalmente diferente da que propõe um ensino médio profissionalizante, caso em que a profissionalização é entendida como um adestramento em uma determinada habilidade sem o conhecimento dos fundamentos dessa habilidade e, menos ainda, da articulação dessa habilidade com o conjunto do processo produtivo.

A concepção politécnica implica a progressiva generalização do ensino médio como formação necessária para todos, independentemente do tipo de ocupação que cada um venha a exercer na sociedade. Sobre a base da relação explícita entre trabalho e educação se desenvolve, portanto, uma escola média de formação geral. Nesse sentido trata-se de uma escola de tipo "desinteressado" como propugnava Gramsci (1975, p. 486-487; na edição brasileira, 1968, p. 123125). É assim que ele entendia a escola ativa e não na forma como essa expressão aparecia no movimento da Escola Nova, isto é, a escola única diferenciada preconizada pela burguesia. E, para ele, o coroamento dessa escola ativa era a escola criativa, entendida como o momento em que os educandos atingiam a autonomia. Realizava-se, dessa forma, o sentido 
gramsciano da escola mediante a qual os educandos passariam da anomia à autonomia pela mediação da heteronomia.

Completa-se, assim, a organização curricular da Educação Básica que, desde a Educação Infantil até o Ensino Médio tem o caráter de uma educação geral comum e universal destinada, portanto, a toda a população.

Da Escola Média passar-se-á à Educação Superior na qual, além do Ensino Superior destinado a formar profissionais de nível universitário (a imensa gama de profissionais liberais e de cientistas e tecnólogos de diferentes matizes), formula-se a exigência da organização da cultura superior com o objetivo de possibilitar a toda a população a difusão e discussão dos grandes problemas que afetam o homem contemporâneo.

\section{Conclusão}

Em suma, na definição da Base Nacional Comum Curricular deve-se considerar com toda a atenção e cuidado o problema do conteúdo da educação a ser desenvolvido no âmbito de todo o sistema de ensino. Está em causa, aqui, a questão do trabalho pedagógico em consonância com o terceiro sentido do conceito de trabalho como princípio educativo.

Conforme os documentos legais, a começar pela Constituição Federal e LDB, a educação tem por finalidade o pleno desenvolvimento da pessoa, o preparo para o exercício da cidadania e a qualificação para o trabalho. Levando-se em conta que esses objetivos se referem indistintamente a todos os membros da sociedade brasileira considerados individualmente, podemos interpretar, com Gramsci (1975, vol. III, p. 1547), que o objetivo da educação é conduzir cada indivíduo até a condição de ser capaz de dirigir e controlar quem dirige.

Fica claro que tal objetivo não poderá ser atingido com currículos que pretendam conferir competências para a realização das tarefas de certo modo mecânicas e 
corriqueiras demandadas pela estrutura ocupacional concentrando-se na questão da qualificação profissional e secundarizando o pleno desenvolvimento da pessoa e o preparo para o exercício da cidadania, tal como se evidencia na proposta divulgada pelo MEC sobre a base nacional comum curricular.

Diferentemente dessa tendência dominante, a organização curricular dos vários níveis e modalidades de ensino no âmbito do sistema nacional de educação deverá tomar como referência a forma de organização da sociedade atual, assegurando sua plena compreensão por parte de todos os educandos. Isso significa que se deve promover a abertura da caixa preta da chamada "sociedade do conhecimento". A educação a ser ministrada deverá garantir a todos o acesso aos fundamentos e pressupostos que tornaram possível a revolução microeletrônica que está na base tanto dos mecanismos de automação que operam no processo produtivo como das tecnologias da informação que se movem nos ambientes virtuais da comunicação eletrônica.

Assim, além de tornar acessíveis os computadores pela disseminação dos aparelhos e em vez de lançar a educação na esfera dos cursos a distância de forma açodada, é preciso garantir não apenas o domínio técnico-operativo dessas tecnologias, mas a compreensão dos princípios científicos e dos processos que as tornaram possíveis. Se continuarmos pelos caminhos que estamos trilhando, não parece exagerado considerar que estamos, de fato, realizando aquelas profecias dos textos de ficção científica que previram uma humanidade submetida ao jugo de suas próprias criaturas, sendo dirigidas por máquinas engrenadas em processos automáticos. Pois não deixa de ser verdade que, cada vez mais, nos relacionamos com as máquinas eletrônicas, especificamente com os computadores considerando-os fetichisticamente como pessoas a cujos desígnios nós nos sujeitamos e, sem conseguirmos compreendê-los, atribuímos a eles determinadas características psicológicas traduzidas em expressões que os técnicos utilizam para nos explicar seu comportamento, tais como: ele, o computador, não reagiu bem ao seu 
procedimento; ele é assim mesmo, às vezes aceita o que você propõe e às vezes não aceita; etc.

Nas condições atuais não é mais suficiente alertar contra os perigos da racionalidade técnica advogando-se uma formação centrada numa cultura de base humanística voltada para a filosofia, literatura, artes e ciências humanas à revelia do desenvolvimento das chamadas "ciências duras". É preciso operar um giro da formação na direção de uma cultura de base científica que articule, de forma unificada, num complexo compreensivo, as ciências humano-naturais que estão modificando profundamente as formas de vida passando-as pelo crivo da reflexão filosófica e da expressão artística e literária. É este o desafio que o sistema nacional de educação terá de enfrentar. Somente assim será possível, além de qualificar para 0 trabalho, promover igualmente 0 pleno desenvolvimento da pessoa e o preparo para o exercício da cidadania.

Espero, enfim, ter indicado, nos limites de um artigo que não pode ultrapassar 60.000 caracteres, a fundamentação teórica e o delineamento dos pontos que devem nortear a elaboração da base nacional comum curricular que permita assegurar a toda a população brasileira uma educação com o mesmo e elevado padrão de qualidade.

\section{REFERÊNCIAS}

GRAMSCI, Antonio (1968). Os intelectuais e a organização da cultura. Rio de Janeiro, Civilização Brasileira.

GRAMSCI, Antonio (1975). Quaderni del carcere. Torino, Einaudi.

MALSON, Lucien (1967). As crianças selvagens: mito e realidade. Porto: Livraria Civilização.

PISTRAK, Moisei (1981), Fundamentos da escola do trabalho. São Paulo: Brasiliense.

RAVITCH, Diane (2011). Vida e morte do grande sistema escolar americano: como os testes padronizados e o modelo de mercado ameaçam a educação. Porto Alegre: Sulina. 
SAVIANI, Dermeval (2007). Educação: do senso comum à consciência filosófica (17 ${ }^{\mathrm{a}}$ ed.). Campinas: Autores Associados.

SAVIANI, Dermeval (2012a), Escola e Democracia (42ª ed.). Campinas: Autores Associados.

SAVIANI, Dermeval (2012b). "O Inep, o diagnóstico da educação brasileira e a Rbep". Revista Brasileira de Estudos Pedagógicos. Brasília, v. 93, n. 234, [número especial], p. 291-322, maio/ago.

SAVIANI, Dermeval (2013). Pedagogia Histórico-Crítica: primeiras aproximações (11 ${ }^{\underline{a}}$ ed.). Campinas: Autores Associados.

SAVIANI, Dermeval (2014). Sistema Nacional de Educação e Plano Nacional de Educação. Campinas: Autores Associados.

TARDIF, Maurice, LESSARD, Claude e LAHAYE, Louise. (1991). "Os professores face ao saber: esboço de uma problemática do saber docente". Teoria e Educação, n. 4, p. 215-233. 